\title{
LPWAN STANDARTLARI TABANLI BİLİŞSEL RADYO AĞLARI İÇİN SPEKTRUM ALGILAMA YAKLAŞIMI
}

\author{
Sercan YALÇIN ${ }^{*}$ \\ ${ }^{1}$ Adıyaman Üniversitesi, Mühendislik Fakültesi, Bilgisayar Mühendisliği Bölümü, Adıyaman, 02040, Türkiye \\ Geliş Tarihi/Received Date: 27.09.2021 Kabul Tarihi/Accepted Date: 20.10.2021 DOI: 10.54365/adyumbd.1001507
}

\begin{abstract}
ÖZET
Bilişsel radyo ağları (Cognitive Radio Networks, CRNs) kullanılarak güvenilir bir spektrum elde edebilmek günümüz kablosuz iletişim teknolojileri ve Nesnelerin İnterneti (Internet of Things, IoTs) uygulamaları için vazgeçilmez olmuştur. Bu çalı̧̧mada, CRN'ler için spektrum algılama yaklaşımında yeni eğilimler incelenmiştir. Düşük güçlü geniş alan ağları (Low Power Wide Area Networks, LPWANs) standartlarından biri olan geniş kapsama (Long Range, LoRa) içerikli CRN'ler ile spektrum algılaması yapılmıştır. Burada amaçlanan, kullanıcıların frekans spektrumlarından maksimum oranda faydalanabilmesini sağlayabilmektir. Daha hassas spektrum algılaması sayesinde haberleşmedeki farklı bant genişliği ve sinyal yayılım faktörlerine bağlı olarak bant genişliği kullanımı verimli hale getirilmiştir. Buna paralel olarak, bant genişliğinde kullanılan miktar artırılarak verimli güç/frekans analizi yapılmıştır.
\end{abstract}

Anahtar Kelimeler: Düşük güçlü geniş alan ağları (LPWAN), Bilişsel Radyo Ağları, Hücresel Ağlar, Nesnelerin Interneti

\section{SPECTRUM SENSING APPROACH FOR LPWAN STANDARDS BASED COGNITIVE RADIO NETWORKS}

\begin{abstract}
Obtaining a reliable spectrum using cognitive radio networks (CRNs) has become indispensable for today's wireless communication technologies and Internet of Things (IoTs) applications. In this study, new trends in spectrum sensing approach for CRNs are examined. Spectrum sensing is performed with Long Range (LoRa)containing CRNs, which is one of the Low Power Wide Area Networks (LPWANs) standards. The aim here is to ensure that users can benefit from the frequency spectrum at maximum rate. Thanks to more sensitive spectrum sensing, bandwidth usage has become more efficient due to different bandwidth and signal spreading factors in communication. In parallel with this, efficient power/frequency analysis has been carried out by increasing the amount of occupied bandwidth.
\end{abstract}

Keywords: Low-Power Wide Area Networks (LPWAN), Cognitive Radio Networks, Cellular Networks, Internet of Things (IoTs)

\section{Giriş}

Nesnelerin İnterneti (Internet of Things, IoTs), cihazlar ve çeşitli amaçlar için kullanılan algılayıcılar arasında ara bağlantı ve veri alışverişini ifade eder. IoT teknolojilerinin büyümesiyle, güvenlik, tarım, akı1lı ölçüm, akı1lı evler ve şehirler, akı1lı ulaşım sistemleri de dâhil olmak üzere birçok alanda artan sayıda pratik uygulama bulunabilir. IoT uygulamalarının uzun menzil, düşük veri hızı, düşük enerji tüketimi ve maliyet etkinliği gibi belirli gereksinimleri vardır. Yaygın olarak kullanılan ZigBee, Bluetooth veya Wimax kısa menzilli radyo teknolojileri, uzun menzilli iletim gerektiren senaryolar için uyarlanmamıştır. Hücresel iletişimlere dayalı $2 \mathrm{G}, 3 \mathrm{G}, 4 \mathrm{G}$ ve $5 \mathrm{G}$ gibi çözümler daha fazla kapsama alanı sağlayabilir, ancak aşırı enerji tüketimi gerektirir. Bu nedenle, IoT uygulamalarının gereksinimleri, LPWAN olarak yeni bir kablosuz iletişim teknolojisinin ortaya çıkmasına sebebiyet vermiştir $[1,2]$.

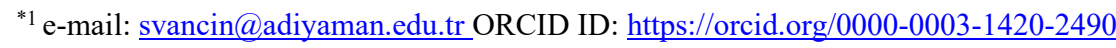


Kablosuz iletişimde verimli spektrum kullanımı, birçok teknoloji için ilgi çekici bir araştırma alanı haline gelen bir konudur. Son zamanlardaki teknolojik yenilikler, kablosuz cihazların çok uzun mesafelerde güç verimli iletişim ile çalışmasına olanak tanır. Örneğin, LPWAN'lar, IoT ağları oluşturmak için gelişmekte olan yenilikçi bir platformdur. Özellikle geniş kapsama standardı (Long Range, LoRa) LPWAN teknolojilerinden biridir ve IoT için bir altyapı çözümü olarak kabul edilir. Uç cihazlar, bir köprü görevi gören ve bu LoRa uç cihazları arasındaki mesajı merkezi bir ağ sunucusuna ileten internete bağlı ağ geçitleriyle iletişim kurmak için tek bir kablosuz atlama üzerinden LoRa protokolünü kullanır $[3,4]$. Bu tür uzun menzilli ağ iletişimi için endüstriyel, bilimsel ve tıbbi bant (Industrial Scientific Medical band, ISM) spektrum paylaşımının kullanılması, araştırmacıları bilişsel radyo ağları (Cognitive Radio Networks, CRNs) için spektrum algılama konusuna yönlendirmektedir. Bilişsel radyoda, ikincil kullanıcılar (Secondary Users, SUs), birincil kullanıcıların (Primary Users, PUs) yokluğunda lisanslı spektrum bandına firsatçı bir şekilde erişmek için bu bilgileri algılayabilir ve kullanabilir. CRN, akıllı bilişsel radyo kablosuz kullanıcıları ve dinamik spektrum erişim yeteneklerinden oluşan bir ağ olarak tanımlanabilir [5,6]. CRN'ler ilk olarak, lisanssız spektrum bandı kullanıldığında karşılaşılan spektrum kıtlığı ve ağ tıkanıklığı sorununu çözmeye çalışırken tanıtılmıştır. Lisanssız spektrum bandında, akıllı bilişsel radyo iletişim cihazları, spektrum kıtlı̆̆ gerçeğine dayanarak, SU'lar olarak adlandırılmış bilişsel radyo kullanıcılarına lisanslı spektrum bandına erişim ve orijinal kullanıcıları ile paylaşma izni verir. Ancak, bu paylaşımda, PU'lar olarak adlandırılmış orijinal kullanıcıların performansının etkilenmeyeceği garantisini vermek zorundadır [6]. Çünkü bilişsel radyo, PU'ların işlemlerine zararlı bir şekilde müdahale edebilir. Dolasıyla, bilişsel radyoda verimli bir spektrum algılaması, karar vermesi ve spektrumun yönetilmesi zorlu bir görevdir. Ancak, spektrum algılamasında, spektrum deliği için enerji tespiti ve tüketimi radyo ağının verimliliği açısından hassas bir görevdir. Bu yüzden düşük enerji tüketen kablosuz teknolojilerin bu görevde yer alması, enerji verimliliği açısından avantajlı olacaktır. İşte bu nedenle, bu çalışmada, LPWAN standartlarından güncel olan teknolojiler incelenmiş ve bu teknolojilerden LoRa'nın CRN'lerde spektrum algılamasında son zamanlarda araştırmacıların da çalışma materyali olduğu görüldüğünden ötürü, bu teknolojinin bu çalışmada da kullanılmasının yararlı olacağı anlaşılmıştır. Bu anlamda çalışmada, CRN'ler için LoRa kullanılarak spektrum algılama yöntemi planlanmıştır. Deneysel uygulamalar Matlab benzetim ortamında gerçekleştirilerek elde edilen sonuçlar irdelenmiştir. Ayrıca bu çalışma, Microchip LoRa evrim kitleri, evrensel yazılım radyo çevre birimleri (USRP) ve GNU radyo kullanılarak yapılabilir. Bu anlamda yazılım tanımlı radyo ağları sisteme bütünleştirilmektedir.

$\mathrm{Bu}$ çalışmanın ana katkıları şu şekilde sıralanabilir.

- Bu çalışmada, güncel LPWAN teknolojilerinden biri olan LoRa tabanlı bilişsel radyo ağları için spektrum analizi yapılmıştır. Bu sayede efektif bant kullanımı yapılmış ve güç/frekans dağılımı incelenmiştir.

- Diğer çalışmaların aksine, LoRa ve bilişsel ağlar bir arada düşünülerek kablosuz ağ teknolojileri ve yeni nesil hücresel ağlar için bir takım önerilerde bulunulmuştur.

- Yapılan deneysel çalışmalar ile bilişsel radyo ağında spektrum yayılım faktörü kullanımının önemi vurgulanmıştır.

Bu makalenin geri kalanı şu şekilde özetlenebilir. Bölüm 2'de, araştırma konusuyla ilgili çalışmalardan bahsedilmiştir. Bölüm 3'te, güncel ve popüler LPWAN standartları açıklanmıştır. Bölüm 4'te, LoRa kullanan CRN'lerin spektrum algılaması adıyla materyal ve metot sunulmuştur. Bölüm 5 'te, deneysel uygulama anlatılarak benzetim sonuçları irdelenmiştir. Son olarak Bölüm 6'da, makale çalışması sonuçlandırılarak çeşitli önerilerde bulunulmuştur.

\section{2. İlgili Çalışmalar}

IoT erişim noktaları veya ağ geçitleri, kapsamları içinde bulunan IoT uç cihazlarına erişim sağlar. $\mathrm{Bu}$ ağ geçitlerinin konumları ve yükseklikleri, spektrum girişimi ve antenler, belirli bir yayılma ortamı için sağlanan kapsama alanını yönetir. A $\breve{g}$ tasarımı ve planlaması, ağın bağlanabilirlik ve kapasite 
gereksinimlerini karşılamak amacıyla bu ağ geçitleri için en uygun fiziksel konumları tahmin etmek için kapsama modellemesiyle yapılır. Elde edilen kapsama alanı, deneysel ölçümler, 1şın izleme benzetimleri veya her ikisinin bir karışımı yoluyla elde edilen yayılma modellemesi yoluyla yakalanan ağın radyo ortamına dayanır. Birçok deneysel model, kablosuz ağlar için belirli kırsal ve kentsel yoğunluk yayılım ortamlarındaki gerçek ölçümlere dayalı olarak türetilmiştir $[7,8]$. Bu modeller daha sonra, farklı parametrelerine dayalı olarak benzer yoğunluk yayılım ortamları için bir tahmin sağlamak üzere genelleştirilir [9]. Hibrit yayılma modellemesi, orta bir karmaşıklık ve güvenilirlik noktası elde etmek için hem deneysel modelleri hem de 1şın izlemeyi birleştirir. Bir dijital iletişim bağlantısının performansını tahmin etmek için tipik olarak paket hata oranı (PER) eğrileri elde edilir. LoRa için en basit PER eğrisi, ek beyaz Gauss gürültüsüne (AWGN) sahip bir kanal içindir. Eşik sinyal gürültü oranları (SNR), LoRa alıcı-verici tedarikçisi Semtech tarafından alıcı veri sayfasında sağlanmaktadır [10]. Bazı çalışmalarda, parazitin yalnızca ağdan üretildiğini varsayarak, LoRa'nın performansını tahmin etmek için matematiksel modeller türetmek için stokastik geometri gibi diğer araçlar kullanılmıştır [11-13]. Tipik olarak mobil geniş bantta konuşlandırılan kablosuz ağ tasarım platformları da IoT ağlarını içerecek şekilde geçiş yapmakta ve çeşitli benzetimler yoluyla hata eğrilerini elde etmek için ışın izleme veya hibrit teknikler kullanmaktadır. Bu teknikler mobil geniş bant veya lisanslı IoT teknolojileri için yeterli olsa da, spektrumda var olan girişim seviyelerindeki önemli farklılıklar nedeniyle aynı şey LoRa gibi paylaşılan spektrumlu IoT teknolojileri için geçerli değildir. IoT spektrumunda mevcut olan girişimin, ortalamasını yetersiz ve çoğu zaman gerçekçi bir dağıtımın yanlış bir temsilini yapan geçici bir korelasyona (ilgileşim) sahip olduğu gösterilmiştir. Diğer bir çalışmada, yazılım tanımlı radyoların (Software defined radio, SDR) daha pahalı LoRa alıcılarının yerini almasını sağlamak için GNU radyo uygulamaları için LoRa'nın modülasyon ve kodlama şemasını kullanmıştır $[14,15]$. Bununla birlikte, bu uygulamalar ağ tasarımı amaçları için bir platform sağlamamaktadır. Bir çalışmada, Matlab komut dosyası kullanılarak oluşturulmuş bir açık kaynaklı emilatörü kullanan bir LoRa ağ tasarım çerçevesi sunmaktadır [16]. Bu emülatör, LoRa'nın modülasyon ve kodlama şemasına dayalı olarak LoRa sinyallerini simüle eder. Ayrıca, emülatör, sinyallerin radyo yayılımını daha doğru bir şekilde tahmin etmek için araziyi ve bina ayak izlerini birleştirmek için ışın izlemeyi kullanır. Ayrıca, emülatör, spektrum girişimini dâhil etmek için bir SDR'den alınan ölçümleri kullanır.

\section{LPWAN Standartları}

LPWAN teknolojisi, yeni bir teknoloji standardı olarak değil, makineden makineye (Machine to Machine, M2M) ve IoT cihazlarının ihtiyaçlarına göre ortaya çıkmış bir kablosuz teknolojidir. IoT cihazlarının çoğunda, özellikle akıllı şehir ve endüstri sektörlerinde olmak üzere, müşteri hücresel cihazlarının hız ve bant genişliği aynı değildir. Bununla birlikte, geleneksel Uzun Vadeli Evrim (Long Term Evolution, LTE) hücresel ağların uzun ömürlü olmaları gerekmektedir [17].

Küresel sistem mobil iletişim (Global System Mobile Communication Association, GSMA) kablosuz endüstrisi birliği, ağ operatörlerinin IoT uygulamalarının belirli maliyet, kapsama alanı ve güç tüketimi ihtiyaçlarını karşılamasına yardımcı olmak için IoT ve Endüstri 4.0 uygulamaları için LTE-M ve NB-IoT standartları geliştirmiştir. Aynı zamanda LoRa Alliance, düşük bant genişliği, düşük gecikmeli IoT uygulamaları için başka bir kablosuz bağlantı seçeneğini de ekleyerek ortaya çıkan başka bir LPWAN teknolojisini güçlendirmek için kurulmuştur. LPWAN teknolojileri, mevcut ağlardan, küresel erişimden ve güçlü yerleşik güvenlikten yararlanan düşük maliyetli ve güç tasarruflu kablosuz bir seçenek sunarak IoT çözümleri için çalışma verimini artırır. M2M ve IoT cihazları için özel olarak oluşturulan LPWAN teknolojisi düşük güç tüketimi, uzun menzilli kablosuz bağlantı sağlar $[9,18]$.

LPWAN teknolojisi, IoT cihazlarının tek bir pil şarjı ile 10 yıla kadar güvenilir bir şekilde çalışmasını sağlar. Bu süre, şarj için güvenilir bir güç kaynağı bulunmayan sınırlı hareket kabiliyetine sahip çözümler için idealdir. LPWAN teknolojileri genelde aşağıdaki uygulamalar için idealdir $[3,4,19]$.

- Akıllı sayaçlar,

- Akıllı şehir,

- Takip ve izleme, 
- Akıllı tarım,

- Ak1llı bina uygulamaları

LPWAN teknolojisi, 10 ile 1600 bayt arasında değişen küçük aralıklı veri paketlerinde veri aktarımını destekler. Bu aktarım, gelişmiş verimlilik ve $3 \mathrm{~Kb} / \mathrm{s}^{\prime}$ den $375 \mathrm{~Kb} /$ s'ye kadar optimize edilmiş hızlara izin verir. LPWAN daha yüksek güç ve bant genişliği verimliliği ile ve daha geniş bir alanda çalıştığ 1 için daha az altyapı ve donanıma ihtiyaç duyar. Bu özellikler daha yüksek maliyet verimliliğine dönüşür. Kablosuz ağlar ve teknolojiler sürekli gelişmeye devam ettikçe, bağlı cihazlar zaman zaman ürün yazılımı güncellemeleri gerektirebilir. Bu gereklilik, LPWAN standartları için bir zorluktur, çünkü büyük bir güç çekişi ve bant genişliği gerektirir. Bu tür güncelleme pili bitirebilir ve ömrünü kısaltabilir. Bunun yanında, çoğu kez IoT iş durumunu bile yok edebilir [3,4]. Artan güncelleme yeteneklerine sahip bir IoT modülü seçmek, uzun ömürlü ve LPWAN'a yapılan yatırımı korurken, zamandan ve güçten tasarruf etmek için kritik bir uygulamadır.

LPWAN teknolojisi, SigFox, LoRa, LTE-M ve NB-IoT ve EC-GSM-IoT gibi birçok standard1 barındırır. Mevcut ve gelişmekte olan tüm seçeneklerden LTE-M ve NB-IoT, IoT uygulamaları için tercih edilen LPWAN teknolojileri olarak öne çıkmıştır. Bunun nedeni, maliyet verimliliğini esas almasından ve bu standartların uzun ömürlü ve güvenlik farkındalı, geniş kapsamlı ağlar sağlama yeteneğinden kaynaklanmaktadır [20,21]. Bazı güncel LPWAN teknolojileri özetle şu şekilde açıklanabilir.

\subsection{Sigfox Standardı}

Sigfox, patentli teknolojilerine dayanan uçtan uca IoT bağlantı çözümü sunan bir LPWAN ağ standardıdır. Sigfox, bilişsel yazılım tanımlı radyolarla donatılmış tescilli baz istasyonlarını dağıtır ve IP tabanlı bir ağ kullanarak arka uç sunuculara bağlar. Bu baz istasyonlara, ultra dar bant $(100 \mathrm{~Hz})$ subGHz ISM bant taşıyıcısında ikili faz kaydırma anahtarlama (BPSK) modülasyonu kullanılarak uç cihazlar bağlanır. Sigfox, Avrupa'da $868 \mathrm{MHz}$, Kuzey Amerika'da $915 \mathrm{MHz}$ ve Asya'da $433 \mathrm{MHz}$ olmak üzere lisanssız ISM bantları kullanır [1,4].

\subsection{LTE-M Standardı}

LTE-M, 3. Nesil Ortaklık Projesi (3rd Generation Partnership Project, 3GPP) standartlar organizasyonu tarafından yayımlanan bir LPWAN standardı olan endüstri kavramıdır. Genellikle birinci nesil hücresel LPWAN teknolojilerinden biri olarak kabul edilen LTE-M, mevcut LTE ağlarından yararlanır ve içeride ve yerde geniş kapsama alanı ile yüksek verimli bağlantı sağlar. Birden fazla GSM bandında verimli bağlantı sağlayarak cihaz karmaşıklı̆ııı büyük ölçüde azaltır, böylece birden fazla modüle ve varyanta olan ihtiyacı ortadan kaldırır. Şekil 1'de, LTE-M'yi IoT pazarına sunan Cinterion ${ }^{\circledR}$ EMS31 IoT kablosuz modülü gösterilmiştir. LTE-M, 10 y1l veya daha uzun pil ömrü sağlayan güç tasarruflu performans sağlar ve $300 \mathrm{Kbps}$ aşağı bağlantı ve $375 \mathrm{Kbps}$ yukarı bağlantı IoT için optimize edilmiş hızlara sahiptir. EMS31 LTE-M modülü, her türlü çözüm ihtiyacını karşılamak için artımlı ve tam güncelleme özelliklerinin avantajını sunar $[1,2]$.

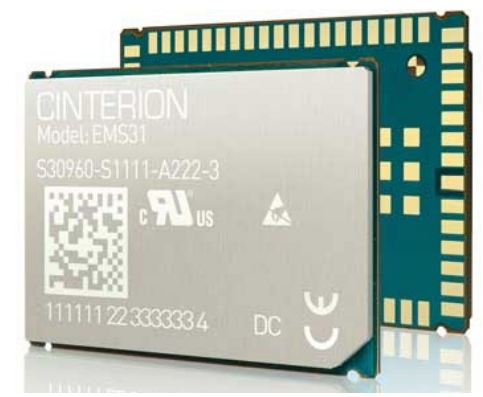

Şekil 1. Cinterion EMS31 IoT kablosuz modülü [4] 


\subsection{NB (Dar Bant, Narrow Band)-IoT Standardı}

LPWAN standartlarından biri olan NB-IoT veya Narrowband IoT, hücresi başına 50.000'e kadar IoT cihazını bağlayabilir. Böylece, LTE-M'nin maliyet ve güç verimliliğini IoT ağlar için oldukça genişletmiştir. NB-IoT, ağ verimliliğini yeni boyutlara taşıyarak, mevcut spektrumun sadece bir kısmını kullanarak çok sayıda yeni bağlantıyı destekler. Bu verimlilik, 10 yıldan fazla pil ömrü sağlayarak güç tüketimini en aza indirir. NB-IoT, yeraltına ve kapalı alanlara nüfuz ederek içeride $20+\mathrm{dB}$ kapsama alanı sağlar. NB-IoT, 700MHz, $800 \mathrm{MHz}$, and $900 \mathrm{MHz}$ bantlarında çalışabilir ve 1600 bayt veri paketlerinde veri aktarımını destekler. Yaklaşı $1 \mathrm{~km}$ kentsel alanda, $10 \mathrm{~km}$ kırsal alanda kapsama alanında etkili bir şekilde çalışabilir [2,3,6].

Bazı araştırma şirketleri, önde gelen bağlantı IoT modüllerini geliştirmek için güçlerini birleştirerek NB-IoT'yi hızlandırma konusunda uğraşmaktadır. Örneğin bir şirket, NB-IoT'nin kısa zamanda tüm hücresel gönderilerin yüzde 20'sini oluşturacağını tahmin ediyor. Yapılan en son tahmin, 2025 yılına kadar 75 milyardan fazla akıllı cihazın aktif olarak kullanımda olacağını tahmin etmektedir. Bu da, günümüzde kullanılan yaklaşık 15 milyar cihaz üzerinde \% 400'lük bir artışın olacağı anlamına gelmektedir. Bu teknoloji pazarında milyarlarca gerçekleşen yeni bağlantıya geçiş yapılmaktadır ve hücresel mobil ağ operatörleri milyarlarca yeni müşteriyi destekleyebilecek teknolojilere büyük yatırım yapmaktadır. Bunun nedeni, büyük çoğunluğunun en iyi düşük bant genişliği, uzun pil ömrünü destekleyen yüksek verimli bağlantı ile sunulan endüstriyel IoT çözümleri olmasıdır. Geleneksel 4G kablosuz ağlar, bu kullanım durumlarının gerektirdiğinden daha fazla beygir gücü sunar. Ayrıca, IoT uygulamaları, çalışma esnasında pil gücünü azaltabileceği ve cihaz ömrünü kısaltabileceği uzak ortamlarda kesintisiz kapsama alanı gerektirir. Hücresel olanın hücresel olmayan bağlantıya oranı, 5G ve NB-IoT'nin ortaya çıkmasıyla dramatik bir şekilde değişmektir. Bu değişim, hızla büyüyen bir hücresel teknoloji olarak tanımlanır ve 4G LTE frekans bandının sadece bir kısmını kullanarak düşük güçlü, yüksek verimli ve uygun maliyetli bağlantı sunar $[2,3,6]$.

Temelde bu teknoloji, geleneksel hücresel modüllerden daha az karmaşıktır ve tasarım, geliştirme ve dağıtımı basitleştirir. NB-IoT standardı, ağ güvenliği için LTE şifrelemesini kullanır [1]. Ayrıca, LTE mobil ağlarının denenmiş ve gerçek güvenlik ve gizlilik özellikleri şu şekilde sunulabilir.

- Kullanıc kimliği gizliliği

- Varlık kimlik doğrulaması

- Veri bütünlüğg̈

- Mobil cihaz tanımlama

Çeşitli şirketler bağlantı modülleri geliştirmek için stratejik işbirliği yaparak NB-IoT'yi geliştirme yolundadır. Yüksek performanslı NB-IoT yonga setleriyle hücresel bağlantı ve dijital güvenlik esaslı yeni LPWAN IoT modülleri, IoT cihaz üreticilerinin cihazlarının maliyetini ve boyutunu azaltmasına yardımcı olmaktadır. LTE-M, GSMA tarafından açıklandığı gibi, basitleştirilmiş cihaz karmaşıklığını, büyük bağlantı yoğunluğunu, düşük cihaz güç tüketimini, düşük gecikmeyi destekleyen ve LTE kurulu tabanın yeniden kullanılmasına izin verir [3,6,7]. LTE-M konuşlandırması, standart bir LTE taşıyıcısı içinde bant içi veya özel bir spektrumda bağımsız olarak yapılabilir. Mevcut hücresel ağlarda dağıtım yapmak isteyen cihaz üreticileri için cazip bir seçenek sunan geniş bir kullanım grubu sunar. NB-IoT, bağlantı için LTE yayılma teknolojisine karşı dörtlü faz kaydırma anahtarlama (QPSK) modülasyon teknolojisini kullanır. Uzun vadede maliyet tasarrufu sağlayan bir ağ geçidi ihtiyacını ortadan kaldırır. Geliştirilmiş iç mekân kapsama alanı, çok sayıda düşük verimli cihaz desteği, düşük gecikme hassasiyeti, düşük cihaz güç tüketimi, optimize edilmiş ağ mimarisi ile karakterize edilir ve ultra maliyet verimlidir. NB-IoT, LTE-M gibi, standart bir LTE taşıyıcısına bant içi veya özel spektrumdaki dağıtımlar için bağımsız olarak yerleştirilebilir. Ek olarak, NB-IoT bir LTE operatörünün koruma bandına da uygulanabilir. Özetle, hem NB-IoT hem de LTE-M'yi bünyesinde barındırabilen az maliyetli, düşük güç tüketen geniş alanlarda kapsamayi gerçekleştiren çift modlu modül cihazlar yeni nesil hücresel ağlar için geliştirilebilir ve milyarlarca tüketiciye bu hizmet sunulabilir. 


\subsection{EC-GSM-IoT Standardı}

Genişletilmiş kapsama GSM IoT (EC-GSM-IoT), standart tabanlı bir LPWAN teknolojisidir. eGPRS tabanlıdır ve IoT iletişimleri için yüksek kapasiteli, uzun menzilli, düşük enerjili ve düşük karmaşık yapıya sahip hücresel bir sistem olarak tasarlanmıştır. EC-GSM-IoT'de yapılan ve mevcut GSM şebekelerine yapılması gereken optimizasyonlar bir yazılım yükseltmesi olarak yapılabilmektedir. Ayrıca kapsama alanı sağlanmaktadır ve pazara çıkış süresi hızlandırılmaktadır. Bu standart ile çok çeşitli kullanım durumları için 10 yıla kadar pil ömrü desteklenebilir. EC-GSM-IOT ağ denemeleri, 2017 için planlanmış ilk ticari girişimlerle başlamıştır. Tüm büyük mobil donanım, yonga seti ve modül üreticileri tarafından desteklenen EC-GSM-IoT ağları, gelecek nesil hücresel mobil ağlar için de varlığını sürdürebilir. Ayrıca, kullanıcı kimliği gizliliği, varlık doğrulama, gizlilik, veri bütünlügü ve mobil donanım tanımlama desteği gibi tüm güvenlik ve gizlilik mobil ağ özelliklerinden yararlanacaktır $[22]$.

\subsection{LoRa Standardı}

LoRaWAN hücresel olmayan bir LPWAN teknoloji standardıdır. Özellikle pille çalışan cihazlara yöneliktir ve karmaşık yerel kurulumlara gerek kalmadan IoT çözümleri arasında birlikte çalışabilirlik sağlar. LoRa cihazları şifreleme ve kimlik doğrulaması için SIM veya MIM olmadan çalıştığından, genellikle ek bir dijital güvenlik katmanı gerektirir. LoRa, tescilli bir yayılma spektrumu tekniğini yani lisanslı olarak kullanılarak alt-GHZ ISM bandındaki sinyalleri modüle eden fiziksel bir katman teknolojisidir. LoRa, Sigfox gibi, Avrupa'da 868 MHz, Kuzey Amerika'da 915 MHz ve Asya'da 433 MHz olmak üzere lisanssız ISM bantlarını kullanmaktadır [22,23].

\section{LoRa Kullanan Bilişsel Radyo Ağlarının Spektrum Algılaması}

$\mathrm{Bu}$ bölümde, LoRa standardı kısaca açıklanarak WAN tabanlı spektrum algılama mimarisi sunulmuştur. Ayrıca, CRN'lerin LoRa ile spektrum algılama yöntemi de verilerek çalışma için gerekli materyal ve metot oluşturulmuştur.

Birçok kablosuz IoT uygulaması, birkaç aydan birkaç yıla kadar değişen uzun pil ömrü gerektirir. Bu tür uygulamalar, Long Range (LoRa) teknolojisinin yükselişi de dâhil olmak üzere düşük güçlü geniş alan ağlarındaki son gelişmeleri motive etmiştir. Bundan ötürü CRN'lere uyumlu çalışabilen LoRa bu çalışmanın ilgi odağı olmuştur.

Şekil 2, LoRa tabanlı bir WAN mimarisini göstermektedir.

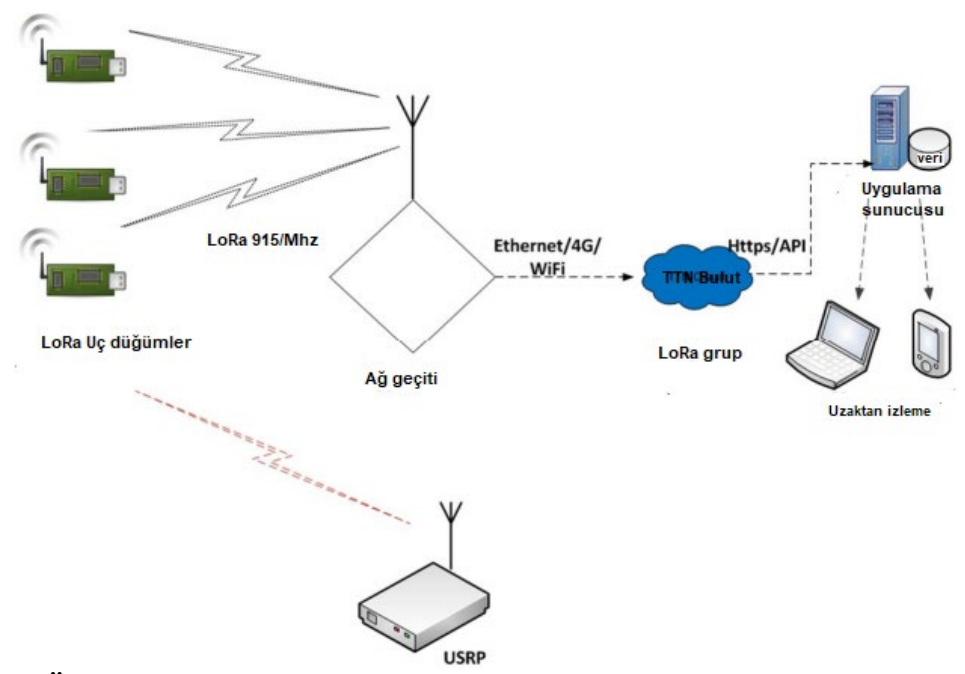

Şekil 2. Örnek bir LoRa ve WAN tabanlı spektrum algılama mimarisi [23] 
Şekil 2'de gösterilen tipik bir LoRa-WAN ağı, uç cihazlar vasıtasıyla kablosuz ortamdan gelen paketleri bir ana taşıyıcı arayüzüne ileten çoklu ağ geçitlerinden oluşur. Bu sayede toplanan bilgileri analiz eden mantıksal olarak merkezileştirilmiş bir sunucu, tüm cihazları ve ağ yapılandırmasını koordine eder. Uç cihazlar, ağa erişim sağlamak için belirli bir ağ geçidiyle ilişkilendirilmez. A $\breve{g}$ geçidi basitçe bir bağlantı katmanı olarak hizmet eder ve uç düğümlerden alınan tüm paketleri ağ sunucusuna iletir. Aynı paketler birden fazla a ğ geçidi tarafından da iletilebilir ve merkezi sunucu, yinelenen paketleri algılamaktan ve aşağ 1 bağlantı paketlerini iletmek için uygun ağ geçidini seçmekten sorumludur. LoRa-WAN ağ geçitleri, yapılandırılabilen birden fazla frekans kanalında eşzamanlı olarak almak için birden fazla alıcı-verici ile donatılmıştır. Uç cihazlar ise her iletim aşamasında birden fazla mevcut kanal arasından bir iletim kanalını dinamik olarak seçebilir. LoRa-WAN, cihazların karmaşıklı̆ını ve enerji tüketimini en aza indirmek için basit bir Aloha protokolüne dayanan açık kaynaklı bir MAC katmanı sağlar. Uç düğümler, taşıyıcı algısı gerçekleştirmezler, ayrıca, yukarı bağlantı iletiminden sonra yalnızca belirli zaman pencerelerinde paketleri almak için ortamı dinlerler [24,25]. MAC katmanı A, B ve C olmak üzere üç sınıftan oluşur.

i) Sınıf A: Bir paketin iletilmesinden sonra her uç cihazın bir alındı mesajı (ACK) almak için iki alım penceresi açtı̆̆ı, ardından boş modda kaldıkları iki yönlü iletişime izin verir.

ii) Sınıf B: Uç aygıtlar, ağ geçidi tarafından sağlanan işaret ile senkronize edilmiş daha fazla alım penceresine sahiptir. Sunucunun uç aygıtların ne zaman dinlediğini bilmesini sağlar.

iii) Sınıf C: Uç cihazlar sürekli olarak alım modunda kalır ve bu da onları pille çalıştırma için uygun hale getirmez.

Bilişsel radyo işlevleri çoğunlukla Spektrum Algılama, Spektrum Yönetimi, Spektrum Hareketliliği ve Spektrum Paylaşımı olmak üzere dört ana işleve ayrılır [25]. Şekil 3, dört CRN işlevi dâhil olmak üzere bilişsel radyo döngüsünü göstermektedir [26, 27]. Bu işlevlerin her biri büyük bir araştırma alanıdır. Bu çalışmada, daha çok spektrum algılaması ve doldurulmasına odaklanılmıştır.

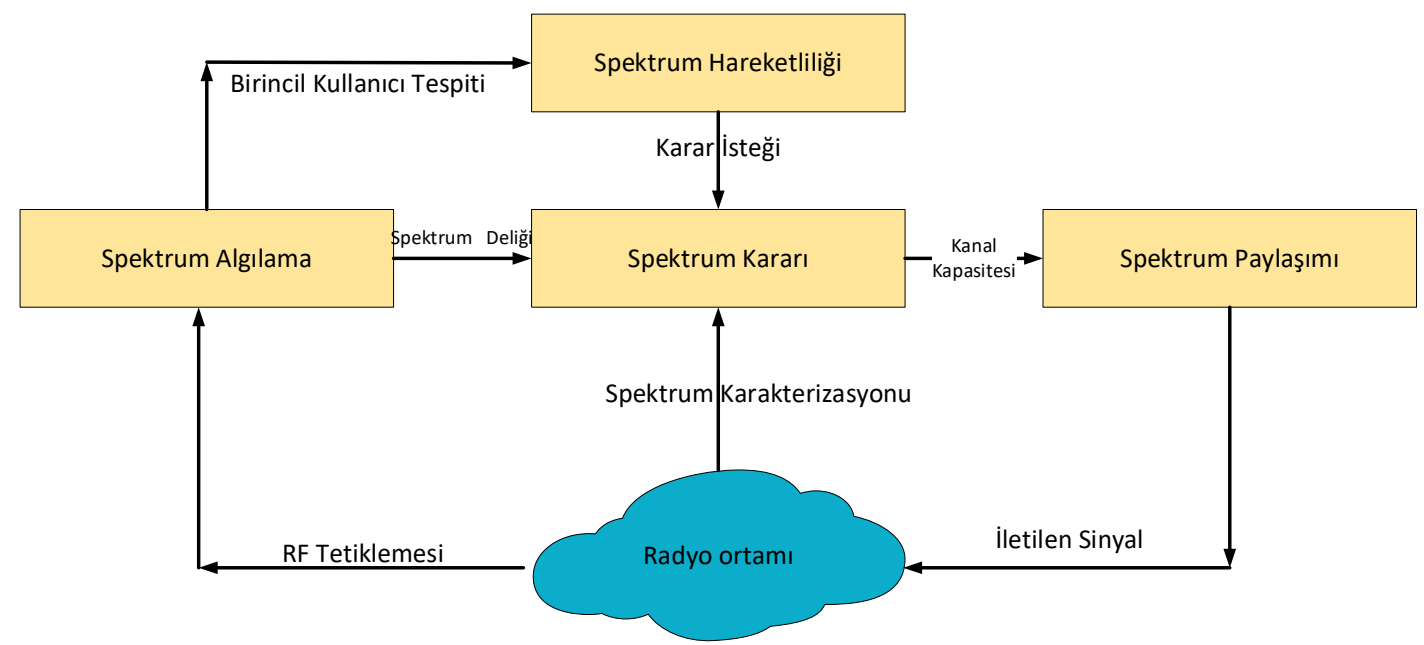

Şekil 3. Bilişsel Radyo Döngüsü

Spektrum algılama, bilişsel radyo tarafından gerçekleştirilen en önemli işlev olarak tanımlanabilir [28]. Bilişsel radyonun çevresindeki herhangi bir değişikliğin farkında olması ve olayları algılaması için spektrum algılaması yapılmalıdır. Spektrum algılama, çevreleyen lisanslı spektrum bandını izlemekten, bilgilerini toplamaktan sorumludur, bu bilgilere dayanarak, Şekil 3'te gösterildiği gibi spektrum deliklerinin kullanılmayan kısmını belirler. Ancak, bazen PU'ların iletimini tespit etmek kolay olmadığı için, spektrum deliklerini tespit etmek basit bir iş değildir. Bu görev, PU'ların iletimine müdahale etmeden yapılmalıdır. Çeşitli araştırmalar, spektrum algılama tekniklerini verici algılama, ortak algılama ve girişim tabanlı algılama olmak üzere üç kategoride sınıflandırmıştır [28,29]. 
Spektrum algılamanın temel görevi, lisanslı PU'ların belirtilen frekans bandında spektrum kullanımının farkındalığını elde etmektir. SU'lar, spektrum algılama işlemi tarafından sağlanan bilgilere dayanarak spektral deliklerin olup olmadığına karar verebilir. Enerji algılama (ED) algılanan enerjiye dayalı olarak PU sinyalini tespit eden tutarlı olmayan bir yöntemdir [30]. ED yöntemi ile mevcut radyo kaynağının enerjisi ölçülür ve önceden tanımlanmış bir eşik seviyesiyle karşılaştırılır. Ölçülen enerji eşik seviyesinin altındaysa, spektrum mevcut olarak işaretlenir, aksi takdirde enerji seviyesi eşiğin üzerindeyken spektrum dolu olarak belirlenir. ED yöntemi, önceden PU sinyali bilgisine ihtiyaç duymaz. Yalnızca bantta alınan enerjiye dayanır. PU yoksa ED yalnızca gürültüyü ölçer, aksi takdirde PU varlığında sinyal artı gürültü enerjisini ölçer. Ortamda PU'nun yokluğu veya varlı̆̆ $H_{0}$ ve $H_{1}$ olmak üzere ikili hipotez ile tanımlanabilir. SU'daki $i$. cihazdan alınan sinyal $Y_{i}$, Denklem 1'deki gibi ifade edilir [31,32].

$$
Y_{i}= \begin{cases}n(i) & H_{0} \\ h(i) s(i)+n(i) & H_{1}\end{cases}
$$

Burada $Y_{i}$, algılama alıcısı (SU) tarafından gözlemlenen karmaşık sinyaldir, $h(i)$, kanalın genlik kazancıdır, $s(i)$, iletilen PU sinyalidir ve $n(i)$, ek beyaz Gauss gürültüsüdür (AWGN). $H_{0}$ hipotezi altında, PU olmadığı kabul edilir ve alınan sinyal örneği $Y_{i}$ yalnızca gürültü içerir. Aksine, $H_{1}$ hipotezi altında alınan sinyal, gürültü ile birlikte $h(i)$ kanalından sonra iletilen sinyalden oluşur. Spektrum algılama işlemi, alınan sinyali gözlemlemeye dayalı ikili hipotez arasında karar vermeyi içerir. PU'nun varlığı, yalnızca frekans bandı dikkate alınarak alınan güç miktarı hesaplanarak ve bir dizi eşik ile karşılaştırılarak tespit edilebilir. PU'nun doluluğuna karar verecek olan ED için test statiği $T_{y}$, Denklem 2'deki şekilde formüle edilebilir [31,32].

$$
T_{y}=\frac{1}{N} \sum_{i=0}^{N-1}|Y(i)|^{2}
$$

Burada $N$, örnek sayısını temsil eder. Her iki hipotez altında $\left(H_{0}\right.$ ve $\left.H_{1}\right)$, test statik $T_{y}$, Gauss dağılımı ile Denklem 3 ve 4 'teki gibi formüle edilebilir [31,32].

$$
\begin{aligned}
& T_{y} \mid H_{0} \sim \xi\left(\sigma_{n}^{2}, \frac{\sigma_{n}^{4}}{N}\right) \\
& T_{y} \mid H_{1} \sim \xi\left(\sigma_{x}^{2}+\sigma_{n}^{2}, \frac{\left(\sigma_{x}^{2}+\sigma_{n}^{2}\right)^{2}}{N}\right)
\end{aligned}
$$

Burada $\sigma_{x}^{2}$ ve $\sigma_{n}^{2}$, sırasıyla iletilen sinyalin ve AWGN'nin varyanslarını gösterir. Karşılık gelen algılama ve yanlış alarm olasılığı, sırasıyla Denklem 5 ve 6 'daki gibi verilebilir [31,32].

$$
\begin{aligned}
& P_{f_{d}}=\operatorname{Pr}\left(T_{y}>\lambda \mid H_{1}\right)=Q\left(\frac{\lambda-\sigma_{n}^{2}(1+\Upsilon)}{\frac{\sigma_{n}^{2}\left(1+Y_{s}\right)}{\sqrt{N}}}\right) \\
& P_{f_{a}}=\operatorname{Pr}\left(T_{y}>\lambda \mid H_{0}\right)=Q\left(\frac{\lambda-\sigma_{n}^{2}}{\frac{\sigma_{n}^{2}}{\sqrt{N}}}\right)
\end{aligned}
$$

Burada $Q($ ), Gauss $Q$-fonksiyonunu gösterir, $\lambda$, önceden tanımlanmış algılama eşiğidir ve $\Upsilon$, SU'da ölçülen PU sinyalinin sinyal parazit gürültü oranını (Signal Interferance Noise Ratio, SINR) temsil etmektedir.

\section{Deneysel Uygulama ve Uygulama Sonuçların Değerlendirilmesi}

Bu bölümde, CRN'ler için LoRa-WAN ağı ve spektrum algılaması için yapılan uygulama ve uygulamanın sonuçları sunulmuştur. Bu çalışmanın uygulaması Matlab yazılımında gerçekleştirilmiştir. 
Bu çalışmada, $915 \mathrm{MHz}$ monopol antene bağlı çok düşük gürültü oranlı bir SDR kullanılmıştır. LoRa tekniğinde, yayılım faktörleri (SF) 7 ile 12 arasında değişmektedir. Ayrıca LoRa, 125, 250 ve $500 \mathrm{kHz}$ 'lik bant genişliklerini kullanmaktadır. Bu çalışmada, sıklıkla kullanılan 10 ve 12 sinyal yayılım faktörleri esas alınmıştır. LoRa modülasyon tekniğinde, bilişsel ağlar ile spektrum algılamasının verimliliğini ölçmek adına iki senaryo düşünülmüştür. İlk senaryoda, $125 \mathrm{kHz}$ 'lik bant genişliğinde ve yayılım faktörü (SF) 10 olduğu bir ağ düşünülmüştür. İkinci senaryoda ise, $250 \mathrm{kHz}$ 'lik bant genişliğinde ve yayılım faktörü (SF) 12 olduğu bir ağ düşünülmüştür. Bu senaryoların amacı, farklı bant genişliğinde ve yayılım faktörlerindeki sinyal frekans dağılımlarını analiz etmektir. Bant genişliğinin ne kadarının kullanımda olduğunu gözlemleyerek verimlilik analizi yapmak bu çalışmanın muhtevasını oluşturmaktadır. SDR, örnekleri seçilen ölçüme dayalı bir zaman serisi olarak toplamaktadır. Matlab programında kullanılan parametreler Çizelge 1'de özetlenmiştir. Yakalanan sinyalin, tipik bir LoRa ağ geçidinden çok daha düşük olan SDR alıcı ek gürültüsünü içermektedir. Böylece, toplanan örneklerin üzerine AWGN'yi enjekte ederek oluşan fark kapatılmaktadır.

Çizelge 1. Uygulama parametreleri

\begin{tabular}{lcc}
\hline \multicolumn{1}{c}{ Parametre } & Değer & Birim \\
\hline Frekans bandı & 915 & $\mathrm{Mhz}$ \\
İletim gücü & 6 & $\mathrm{dBi}$ \\
Alım hassasiyeti & -146 & $\mathrm{dBm}$ \\
SDR örnekleme oranı & 20 & $\mathrm{Mhz}$ \\
LoRa ağ geçidi ölçülen gürülttü rakamı & 6 & $\mathrm{~dB}$ \\
SDR ortalama gürültü & -121 & $\mathrm{dBm}$ \\
LoRa ağ geçiti ortalama gürülttü & -117 & $\mathrm{dBm}$ \\
Mesafe & $>15$ & $\mathrm{~km}$ \\
\hline
\end{tabular}

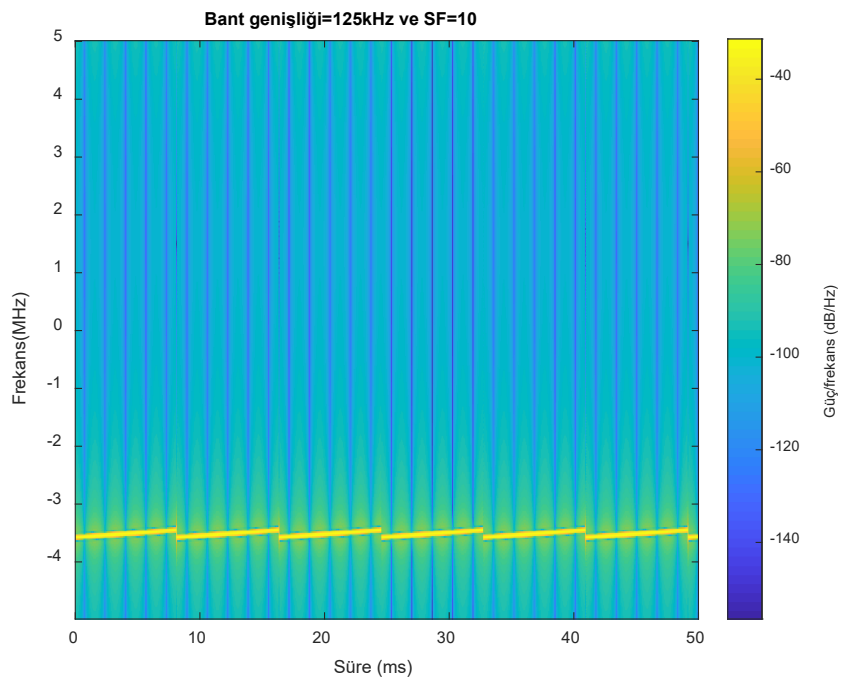

Şekil 4. ISM-bant radyo spektrumunda LoRa iletimlerinin frekans grafiği

İlk senaryoda, toplam $125 \mathrm{kHz}$ bant genişiliği ve yayılım faktörü (SF) 10 olduğunda LoRa performansı analiz edilmiştir. Şekil 4, ISM-bant radyo spektrumunda LoRa iletimlerinin frekans grafiğini sunmaktadır. 50 ms'lik bir frekans dalgası periyodik olarak görünmektedir.

Şekil 5, oluşturulan 13 baytlık bir yüke sahip bir LoRa çerçevesinin iletimini güç/frekans grafiğiyle göstermektedir. 


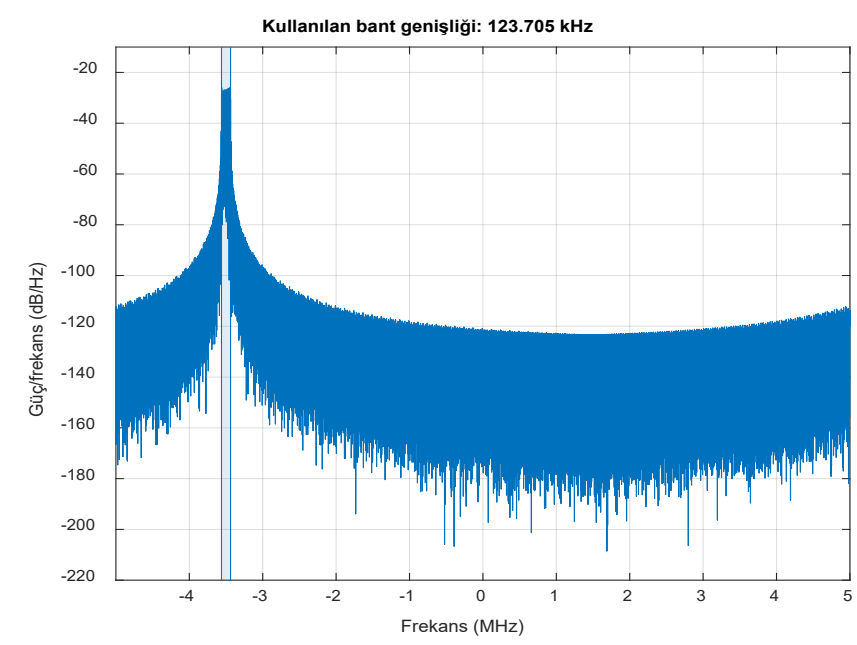

Şekil 5. Oluşturulan 13 baytlık bir yüke sahip bir LoRa çerçevesinin iletimi (Güç/frekans grafiği)

Şekil 5'ten de görüldüğü üzere, kullanılan/meşgul edilen bant genişliği $123.705 \mathrm{kHz}$ olarak hesaplanmıştır. Yani, toplam bant genişliğinin \%98.964'ü kullanılmıştır. LoRa'nın performans ölçümlerinin, ağın farklı konfigürasyonları için istatistiksel veriler sunar. Ayrıca, LoRa-WAN ağının sağlayabileceği hizmet kalitesi (QoS) hakkında fikir vermesi gerekir. LoRa-WAN ağına akan paketler LoRa ağ geçidi tarafından alınır ve gönderilir. Benzetimlerde, LE-Tx, gerçek bir LoRa ile aynı olan bir çerçeve oluşturulmuştur.

Diğer yandan, paylaşılan banttaki mevcut trafiğin spektro-zamansal davranışını kaydeden yazılım içerikli radyo kullanılarak yakalanan girişim ölçümlerinden yararlanılmaktadır. Dolasıyla, bu çalışmada, LoRa ağlarda bilişsel spektrum algılama radyo tekniği ile var olan spektrum delikleri doldurulmuş ve kullanıcıların zararlı parazite neden olan hatalara maruz kalması önlenmiştir. İkinci senaryoda ise, toplam $250 \mathrm{kHz}$ bant genişiliği ve yayılım faktörü (SF) 12 olduğunda LoRa performansı analiz edilmiştir. Şekil 6, ISM-bant radyo spektrumunda LoRa iletimlerinin frekans grafiğini sunmaktadır. Şekil 7'den de görüldüğü üzere, toplam $250 \mathrm{kHz}$ bant genişiliği ve yayılım faktörü (SF) 12 olduğunda, kullanılan/meşgul edilen bant genişliği $246.643 \mathrm{kHz}$ olarak hesaplanmıştır. Yani, toplam bant genişliğinin \%98.657'si kullanılmıştır. Şekil 7, Şekil 6'ya paralel olarak ISM-bant radyo spektrumunda LoRa iletimlerini CRN tabanlı olarak göstermektedir. Şekil 7'den, veri hızı ve frekansı, yayılma faktörüne ve bant genişliğine göre değiştiği açıkça anlaşılmaktadır. Şekil 7'den de anlaşılacağı üzere frekans dengesi optimum hale getirilmiş ve güç /frekans dengesi kararlı hale getirilmiştir.

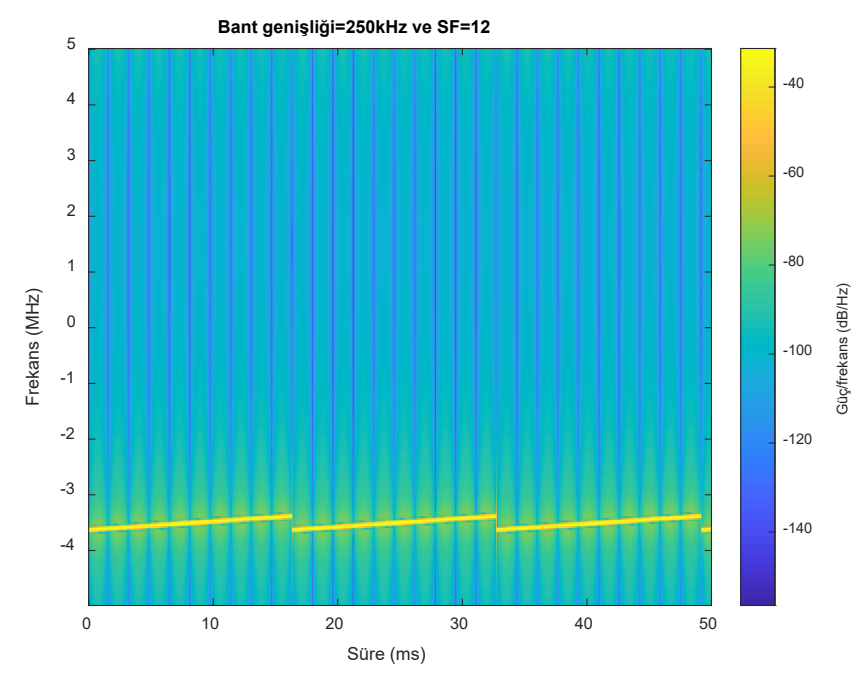

Şekil 6. Bilişsel radyo spektrumunda LoRa iletimlerinin frekans grafiği 


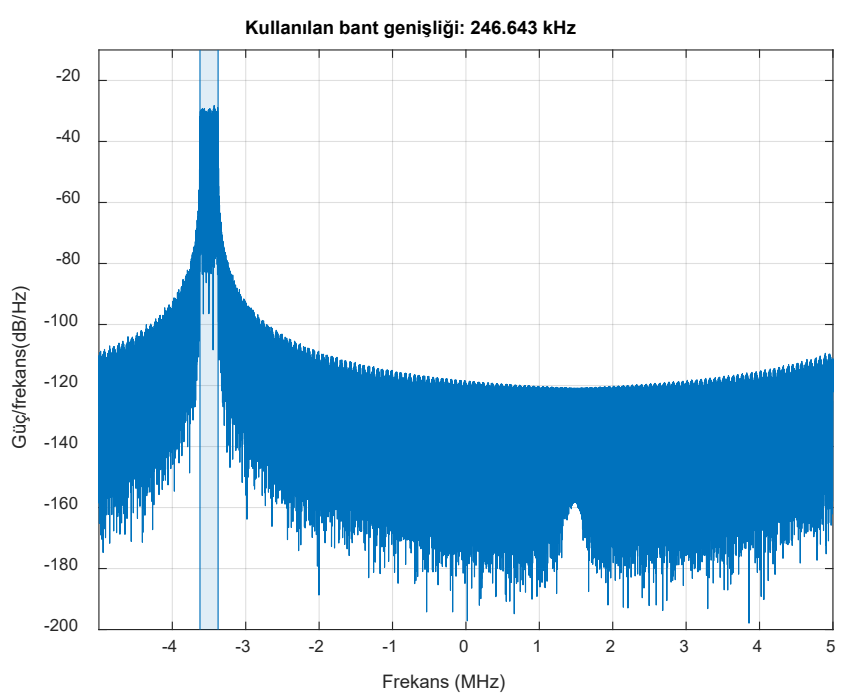

Şekil 7. Bilişsel radyo spektrumunda LoRa iletimleri (Güç/frekans grafiği)

\section{Sonuçlar ve Öneriler}

Bu makalede, LPWAN standartlarından biri olan LoRa içerikli CRN'lerin spektrum algılaması için araştırma ve uygulama çalışması yapılmıştır. Çalışmada bahsedilen uygulama, LoRa modülasyonu ve kodlama şemasına dayalı olarak tipik bir LoRa vericisi veya alıcısından oluşur. Kablosuz iletişimdeki enterferansın yalnızca ortalama bir değer olarak gösterilmesine dayanan geleneksel yöntemlerin aksine, bağlantı performansındaki kendiliğinden değişimleri dâhil etme yeteneğine sahiptir. Bant genişliği ve güç dengesi kurularak spektrum algilama ve tespit etmede avantaj elde edilmiştir. Önerilen metodolojiler ve tasarımlar, herhangi bir yayılma CRN'ler için kullanılabilir ve ağ tasarımcılarına ağın fiziksel dağıtımından önce performansını göstermek için daha doğru yöntemler sağlamasına yardımcı olabilir.

Gelecek çalışmalarda, LoRaWAN standardının MAC katman seviyesinde geliştirilmesi amaçlanmaktadır. LoRa sınıflarında çeşitli yöntemlerle değişimler yaratarak zaman slotlarının ayarlanmasıyla, ikinci alım yuvası olan LoRa standardında RX2, iletim yuvası olan Tx çerçevesinden kaydırılması gerçekleştirilebilir. Bu değişiklik, güvenilir bir yer-uydu hattı aktarımı için güncel kanal parametrelerinin toplanmasına izin verebilir. QoS önemli ölçüde iyileştirilebilir, kabul edilen verimli paket sayısı artırılabilir. Ayrıca, spektrum yönetim analizleri yapılabilir ve ikincil kullanıcıların (SU) boş olan spektrumlardan yararlanması sağlanabilir. Literatürde buna benzer araştırmalar benzetim ortamlarında mevcut olsa da bu yöntemleri gerçek ortam ve donanıma uyarlamak ilgi çekici olabilir.

\section{Kaynaklar}

[1] Mekkia K, Bajica E, Chaxela F, Meyerb F. A comparative study of LPWAN technologies for largescale IoT deployment. ICT Express 2019; 5(1):1-7.

[2] Sanchez-Sutil F, Cano-Ortega A. Smart regulation and efficiency energy system for street lighting with LoRa LPWAN. Sustainable Cities and Society 2021; 70: 102912.

[3] Sinha R, Wei Y, Hwang S. A survey on LPWA technology: LoRa and NB-IoT, J. ICT Expr. 2017; 3:14-21.

[4] Queralta JP, Giaa TN, Zoub Z, Tenhunenc H, Westerlunda T. Comparative Study of LPWAN Technologies on Unlicensed Bands for M2M Communication in the IoT: beyond LoRa and 
LoRaWAN. The 14th International Conference on Future Networks and Communications (FNC). August 19-21, Halifax, Canada 2019:343-350.

[5] Sumathi AC, Vidhyapriya R, Vivekanandan C, Sangaiah AK. Enhancing 4G Co-existence with Wi-Fi/IoT using Cognitive Radio. Cluster Computing 2019; 22:11295-11305.

[6] Onumanyi AJ, Abu-Mahfouz AM, Hancke GP. Low Power Wide Area Network, Cognitive Radio and the Internet of Things: Potentials for Integration. Sensors 2020; 20:6837.

[7] MacCartney GR, Rappaport TS. Rural macrocell path loss models for millimeter wave wireless communications. IEEE Journal on Selected Areas in Communications 2017; 35(7):1663-1677.

[8] Al-Hourani A, Chandrasekharan S, Kandeepan S. Path loss study for millimeter wave device-todevice communications in urban environment. in 2014 IEEE International Conference on Communications Workshops (ICC) 2014: 102-107.

[9] Al-Hourani A. On the probability of line-of-sight in urban environments. IEEE Wireless Communications Letters 2020; 9(8):1178-1181.

[10] SX1276/77/78/79: $137 \mathrm{MHz}$ to $1020 \mathrm{MHz}$ low power long range transceiver, SEMTECH, 2020, [Online]. Available: https://www.semtech.com/ [Erişim: Eylül 2, 2021].

[11] Georgiou O, Raza U. Low power wide area network analysis: Can LoRa scale?. IEEE Wireless Communications Letters 2017; 6(2): 162-165.

[12] Magrin D, Centenaro M, Vangelista L. Performance evaluation of LoRa networks in a smart city scenario. in 2017 IEEE International Conference on Communications (ICC) 2017: 1-7.

[13] Beltramelli L, Mahmood A, Gidlund M, Österberg P, Jennehag U. Interference modelling in a multi-cell LoRa system. in 2018 14th International Conference on Wireless and Mobile Computing, Networking and Communications (WiMob) 2018: 1-8.

[14] Robyns P, Quax P, Lamotte W, Thenaers, W. A multi-channel software decoder for the lora modulation scheme. in Proceedings of the 3rd International Conference on Internet of Things, Big Data and Security IoTBDS,, INSTICC. SciTePress 2018: 41-51.

[15] Knight M, Seeber B. Decoding lora: Realizing a modern lpwan with sdr. Proceedings of the GNU Radio Conference 2016; 1(1).

[16] Homssi B, Dakic K, Maselli S, Wolf H, Kandeepan S, Al-Hourani A. IoT Network Design using Open-Source LoRa Coverage Emulator. IEEE Access 2021: 10.1109/ACCESS.2021.DOI.

[17] Ruckebusch P, Giannoulis S, Moerman I, Hoebeke J, Poorter E. Modelling the energy consumption for over-the-air software updates in LPWAN networks: SigFox, LoRa and IEEE 802.15.4g. Internet of Things 2018; 3(4): 104-119.

[18] LoRa Alliance, "Specification, LoRaWAN," LoRaWAN, 2018, [Online]. Available: https://loraalliance.org/sites/default/files/2018- 07/lorawan1.0.3.pdf [Erişim: September 17, 2021].

[19] Souza Sant'Ana JM, Hoeller A, Souza RD, Alves H, Montejo-Sánchez S. LoRa performance analysis with superposed signal decoding. IEEE Wireless Communications Letters 2020; 9(11):1865-1868.

[20] Beltramelli L, Mahmood A, Osterberg P, Gidlund M. LoRa beyond aloha: An investigation of alternative random access protocols. IEEE Transactions on Industrial Informatics 2020:1-10.

[21] Wang YE, Lin X, Grovlen A, Sui Y, Bergman J. A primer on 3GPP narrowband internet of things. IEEE Commun. Mag. 2016; 55 (3): 117- 123.

[22] Liberg O, Sundberg M, Wang YPE, Bergman J, Sachs J, Wikström G. Chapter 4 - EC-GSM-IoT performance, Cellular Internet of Things (Second Edition). From Massive Deployments to Critical 5G Applications 2020: 125-154.

[23] LoRa Alliance, LoRa modulation basic, and1200.22,(http://www.semtech.com). [Erişim: Ağustos 12, 2021].

[24] Cavo L, Fuhrmann S, Liu L. Design of an area efficient crypto processor for 3GPP-LTE NB-IoT devices. Microprocessors and Microsystems 2020; 72: 102899.

[25] Sethi A, Jain SK, Vijay S. Secure Self Optimizing Software Defined Framework for NB-IoT Towards 5G. Procedia Computer Science 2020; 171: 2740-2749. 
[26] Akyildiz IF, Lee WY, Vuran MC, Mohanty S. NeXt Generation/Dynamic Spectrum Access/Cognitive Radio Wireless Networks: A survey. Computer Networks 2006; 50(13): $2127-$ 2159.

[27] Rao R, Cheng Q, Kelkar A, Chaudhari D. Cooperative Cognitive Radio Network Testbed. ICST's Global Community Magazine 2011: ICaST.

[28] Akhtar AN, Siddique AM. Spectrum Decision Framework to Support Cognitive Radio Based IoT in 5G. in Cognitive Radio in 4G/5G Wireless Communication Systems Book, 2018.

[29] Rateb AM. Introduction to Cognitive Radio Systems. Universiti Teknologi Malaysia, 2008.

[30] Almasoud AMM. Robust Provisioning of Multicast Sessions in Cognitive 160 Radio Networks. in Proceeding of the 10th International Wireless Communications and Mobile Computing Conference (IWCMC) 2014:417-422. doi: 10.1109/IWCMC.2014.6906393.

[31] Tendeng R, Lee Y, Koo I. Implementation and Measurement of Spectrum Sensing for Cognitive Radio Networks Based on LoRa and GNU Radio. International Journal of Advanced Smart Convergence 2018;7(3): 23-36.

[32] Nurelmadina N, Hasan MK, Memon I, Saeed RA, Ariffin KAZ, Ali ES, Mokhtar RA, Islam S, Hossain E, Hassan MA. A Systematic Review on Cognitive Radio in Low Power Wide Area Network for Industrial IoT Applications. Sustainability 2021; 13:1-22. 